\title{
Psychiatric uses of topiramate: What is the current evidence?
}

Pierre M Joubert, MB ChB, FCPsych, MMed (Psych) (SA) Department of Psychiatry, School of Medicine, Faculty of Health Sciences, University of Pretoria and Weskoppies Hospital, Pretoria

Topiramate enhances gamma-amino-butyric acid effects, has antiglutaminergic effects, and is a state-dependent sodium channel blocker.' It is registered as an adjunctive treatment for epilepsy but is not registered for psychiatric indications. Nevertheless, it may be useful beyond its initial indication, considering the promising literature on which I report below. However, much more research evidence is needed to establish sufficient scientific justification for prescribing it routinely for psychiatric purposes.

\section{Eating disorders}

Three randomised, double-blind, placebo-controlled studies on the use of topiramate for bulimia nervosa have been undertaken..$^{2 \cdot 4}$ All reported promising reductions in binging and purging behaviour, as well as body mass. One study specifically reported an improvement in body image, eating attitudes, anxiety and selfesteem. ${ }^{3}$ Treatment was phased in at $25 \mathrm{mg}$ per day, and increased where necessary to up to $400 \mathrm{mg}$ per day. Topiramate appears to have been well tolerated but was discontinued in a small minority of subjects owing to side-effects. These studies were of relatively short duration (10 weeks) on relatively small numbers of subjects $(60-70)$. Barbee reported 5 cases of severe bulimia nervosa with co-morbid mood and/or anxiety disorders. ${ }^{5}$ Three of the 5 patients progressed to almost complete remission on topiramate. The effect was maintained during an 18 months' follow-up period. One subject showed a partial response, and the other could not tolerate topiramate. Two single-case reports also describe that bulimia nervosa responded to topiramate. ${ }^{6,7}$

Appolinario et al. described an open-label trial on 6 obese patients with binge eating disorder without neuropsychiatric co-morbidity, whose eating behaviour and weight improved significantly on topiramate. ${ }^{8}$ Kotwal et al., however, reported on a naturalistic case series of 12 obese patients with bipolar disorder and co-morbid binge eating disorder who received topiramate for obesity and binge eating disorder, but needed lithium augmentation for optimal effect. ${ }^{9}$

A retrospective chart review done by Carpenter et al. found promising results regarding weight loss in the treatment of obese patients suffering from major depressive disorder. ${ }^{10}$ The results were less convincing regarding depression, and the investigators were concerned about central nervous system (CNS) side-effects.

A case was reported of a woman suffering from anorexia nervosa and epilepsy, whose epilepsy was treated with topiramate. After topiramate was started, the anorexia nervosa flared up again. The authors concluded that it might have been precipitated by topiramate.

\section{Obesity/weight gain}

Several studies indicate either as the main aim of that study or as a serendipitous result that topiramate may be useful to manage weight gain. The potential usefulness of topiramate for this purpose is not clear yet, because many psychotropics used concomitantly have weight gain as a side-effect. For example, a study by McElroy ${ }^{12}$ compared sibutramine and topiramate as adjunctive treatment for psychotropic-associated weight gain in adult, obese patients with a diagnosis of bipolar disorder in a randomised, open-label, flexible dose, drug comparison design. The trial lasted 24 weeks and involved 18 subjects on sibutramine (dose $5-15 \mathrm{mg}$ per day) and 28 subjects on topiramate (dose 25 . $600 \mathrm{mg}$ per day). Both treatment groups were associated with similar weight loss. However, the drop-out rates for both groups were high $178 \%$ for sibutramine and $79 \%$ for topiramate), calling into question the real usefulness of these drugs in clinical practice. Roy Chengappa et al..$^{13}$ performed a randomised, double-blind, placebo-controlled trial to assess the efficacy of topiramate as an adjunctive treatment in adults with bipolar I disorder. Although topiramate turned out to be an inefficacious adjunctive treatment, significant weight loss was found when compared with placebo. Although the literature clearly indicates that weight loss can occur on topiramate, it is not registered for that purpose; neither did I find any practice guidelines in this regard.

Weight loss on topiramate has also been described in children suffering from bipolar disorder who gained weight due to psychotropic treatment. The study was small (10 subjects), relatively brief (11 weeks) and had an open-label design. ${ }^{14}$ Of note are the findings of Canitano. ${ }^{15}$ This paper describes children and adolescents with autistic spectrum disorders who gained weight substantially after having received neuroleptics for behavioural control. The study was also small (10 subjects) with an open-label design. Topiramate was slowly titrated up to $1-3$ 
$\mathrm{mg} / \mathrm{kg} /$ day. Six subjects took topiramate on a regular basis; 4 dropped out. Four patients showed variable degrees of weight reduction. Two subjects gained weight. Behavioural adverse effects were observed in 3 patients, necessitating withdrawal of the medication. The author warned that topiramate should be used with caution in autistic spectrum disorders because it may cause behavioural disruption in this group of patients.

\section{Disorders of substance abuse}

\section{Alcohol abuse}

In a randomised, double-blind, placebo-controlled study that received favourable comments, ${ }^{16}$ Johnson et al. ${ }^{17}$ reported that topiramate had a significant effect on abstaining from alcohol among 150 subjects suffering from alcohol dependence. The daily dose was about 200 mg; the study duration was relatively short ( 12 weeks).

Rubio et al. ${ }^{18}$ reported on 24 patients with alcohol dependence with other co-morbid psychiatric disorders '... for which the use of topiramate was indicated'. These patients received topiramate (average dose $262 \mathrm{mg}$ per day) and other psychiatric drugs. They reported that, except for 3 patients who discontinued treatment, topiramate was well tolerated. It seemed that the addition of topiramate decreased the craving for alcohol. The authors concluded that topiramate might be beneficial for alcohol dependence.

Raguraman et al. ${ }^{19}$ described 22 subjects with alcohol dependence who received topiramate 1250 - 300 mg per dayl in an open-label study lasting 12 weeks. Six subjects did not complete the study because of problems with compliance. The treatment was discontinued for another subject owing to the development of a severe depressive episode. They found improvement in reported alcohol-related behaviour. Reported side-effects included psychomotor slowing, depression, memory impairment, concentration impairment, drowsiness and excessive sedation, but no weight loss.

Huguelet and Morand-Collomb described 2 patients lone suffering from schizophrenia, the other from bipolar disorder) with severe co-morbid alcohol abuse. ${ }^{20}$ Komanduri described 2 patients with alcohol abuse. ${ }^{21}$ In both of these case studies, topiramate appeared to improve the alcohol abuse..$^{20,21}$

\section{Smoking}

Johnson et al. ${ }^{22}$ extended their above-mentioned study ${ }^{17}$ to investigate the effect of topiramate on cigarette smoking. They used a double-blind, placebo-controlled design involving 94 subjects over a 12-week period. They concluded that topiramate showed potential for the treatment of cigarette smoking in alcoholdependent individuals. Khazaal et al. ${ }^{23}$ reported on a small number (13) of cigarette smokers who were given topiramate in an open-label trial. After 2 months, 6 of them were abstinent, 3 had a temporary reduction in smoking, and 3 could not tolerate topiramate.

\section{Cocaine}

Kampman et al. ${ }^{24}$ described a 13-week, double-blind, placebocontrolled trial with topiramate as the active medication for the treatment of 40 subjects diagnosed with cocaine dependence. The results indicated that the topiramate-treated subjects were more likely to abstain from cocaine than the placebo-treated subjects. The authors came to the conclusion that topiramate might be effective for the treatment of cocaine dependence.

\section{Borderline personality disorder}

Relatively small and brief randomised, placebo-controlled studies indicate that topiramate may be useful for treating borderline personality disorder (BPD) at dosages of $200 \mathrm{mg}$ per day (that were titrated upwards from $25 \mathrm{mg}$ per day). Loew et al. ${ }^{25}$ studied 56 patients over a 10-week period with promising results. Nickel et al. ${ }^{26}$ studied 29 women with BPD and found significant reductions in anger measurements. Nickel et al. ${ }^{27}$ repeated the study with 42 male subjects suffering from BPD, with similar results. In both the Nickel et al. studies, the dosages were $250 \mathrm{mg}$ per day after titration upwards from $50 \mathrm{mg}$ per day.

Do Prado-Lima et al. ${ }^{28}$ reported a case study of a woman with BPD who responded to topiramate. Cassano et al. ${ }^{29}$ described a 24-year-old woman with bipolar II disorder and BPD who was treated with topiramate in the course of trying to find a drug that controlled her depression; self-mutilation ceased after 2 weeks on 200 mg per day, despite no improvement of her depression. After topiramate had been discontinued, self-mutilation recurred, but ceased again after re-introducing the topiramate.

\section{Anger, aggression and self-injury}

Gobbi et al. ${ }^{30}$ reported on a retrospective, case-controlled, mirrorimage study involving 45 inpatients with marked aggression and agitation who were managed in a maximum-security Canadian psychiatric hospital. The patients were suffering from schizophrenia, schizo-affective disorder and bipolar disorder. The authors compared sodium valproate, topiramate and a combination thereof. Both valproate and topiramate reduced 
aggression, but only valproate reduced agitation. They suggested that topiramate might be useful in the treatment of aggression in psychosis, calling for double-blind randomised, placebocontrolled studies.

Nickel et al. ${ }^{31}$ studied the effects of topiramate on symptoms of anger in women with recurrent major depressive disorder of a mild to moderate degree of severity. They used a randomised, doubleblind, placebo-controlled design involving 64 subjects over a 10-week period. They concluded that topiramate appeared to reduce depressive symptoms and anger. The reduction in anger symptoms was strongly correlated with a reduction in Hamilton Depression Rating Scale scores. The study reported a significant improvement in both depressive symptoms and anger, as well as a correlation between the two. It is however not clear whether the anger improved owing to a selective effect of topiramate on anger or owing to the improvement in the depressive disorder.

Fhager et al. ${ }^{32}$ retrospectively evaluated the outcome of topiramate used on 15 patients suffering from dementia who were severely aggressive and failed to respond to neuroleptics. The dementias were of various types. One group of patients received topiramate alone (8 subjects, mean age 75, standard deviation 6.2) and the other group received topiramate adjunctively 17 subjects, mean age 79.9, standard deviation 6.4). Topiramate dosages were 25 - 150 mg daily. The subjects were assessed with the Cohen Mansfield Agitation Inventory at baseline and after 2 weeks of receiving topiramate. Both groups showed significant improvement in aggressive behaviour. Interestingly, a neuroleptic was added to the group that received topiramate alone, but it conveyed no further benefit. The authors did not comment on sideeffects but acknowledged the limits of the study and suggested double-blind placebo-controlled trials to investigate the possible usefulness of topiramate in patients suffering from dementia.

Kossoff and Pyzik ${ }^{33}$ reported 3 boys, aged 5 - 12 years, with refractory epilepsy who were treated with combination therapy of topiramate and vagus nerve stimulation. All 3 showed a significant reduction in seizures, but what impressed them even more was a dramatic improvement in aggression, social interaction and ambulation. The authors were of the opinion that this was not due solely to seizure reduction, which was observed only differentially at 12 months.

Janowsky et al. ${ }^{34}$ studied the effect of topiramate in an open-label trial on a group of 22 adult, institutionalised, severely to profoundly intellectually disabled individuals. Fifteen had bipolar disorder and 5 had another mood disorder. Other additional disorders included autism, an anxiety disorder, obsessive-compulsive disorder, and no additional psychiatric diagnosis. Subjects also had diagnoses of various general medical conditions. The mean daily dose of topiramate was $202 \mathrm{mg}$ with a range of 150 - 350 mg. The subjects were treated for '... aggression, self-injurious behaviors, destructive/disruptive behaviors or a combination of these, and/or other challenging and maladaptive behaviors'. They were also receiving concurrent psychotropic and/or anticonvulsant medications. There were promising improvements in the global severity scores, cumulative aggression, and worst behaviour rates at 6 months after starting topiramate. There were no significant weight changes. Other complications were noted: 1 patient developed delirium, 1 hypoglycaemia, 1 sedation, and 2 constipation. The authors concluded that topiramate might have a role in the treatment of challenging/maladaptive behaviours in intellectually disabled individuals.

\section{Disorders of impulse control}

In an open-label pilot study involving a small number of patients (14) for a relatively short period (16 weeks), Lochner et al. indicated that topiramate showed promise for use in trichotillomania. ${ }^{35}$ They used a flexible dose of $50-250 \mathrm{mg}$ per day.

After a single-blinded 12-week study of 31 male subjects with a DSM-IV diagnosis of pathological gambling, the authors concluded that both topiramate and fluvoxamine may be effective in the treatment of pathological gambling. ${ }^{36}$ This study was small and of relatively short duration. In a small case series of 3 kleptomanic patients, it was reported that subjects responded well to topiramate given either alone or in combination with an SSRI. ${ }^{37}$

$\mathrm{Grant}^{38}$ described an 18-year-old male with pyromania who received a combination of topiramate $(75 \mathrm{mg}$ per day) and cognitive behavioural therapy (CBT) for 3 weeks. Apparently, topiramate reached a dose of $75 \mathrm{mg}$ after 3 weeks of CBT and 'After 3 weeks of CBT and 1 week of topiramate $75 \mathrm{mg} /$ day, Mr. A denied urges to set fires'. He was considered free from symptoms on topiramate 20 months later.

\section{Post-traumatic stress disorder}

Berlant and Van Kammen ${ }^{39}$ performed a naturalistic data review of medical records involving 35 adults who were treated for DSM-IV chronic post-traumatic stress disorder (PTSD). Some were treated with topiramate (12.5 - $500 \mathrm{mg} /$ day) as monotherapy (7 patients), but most received topiramate as add-on treatment 
(28 patients). The mean duration was 33 weeks (range 1 - 119 weeks). Nightmares, flashbacks and intrusive thoughts decreased significantly after topiramate had been introduced. There were also significant improvements in avoidance and hyperarousal. They reported a relatively rapid onset within 1 - 2 weeks. One instance of narrow-angle glaucoma occurred. Their conclusion was that double-blind studies were indicated. The same conclusion was reached after a small (3 subjects) case series of adults with chronic PTSD. ${ }^{40}$

\section{Mood disorders}

Initially, topiramate seemed an encouraging candidate in the treatment of bipolar disorder and its subtypes, especially rapid cycling. ${ }^{41}$ However, double-blind placebo-controlled trials failed to support topiramate as monotherapy or as add-on therapy for any of the phases of bipolar disorder. ${ }^{13,42-44} \mathrm{~A}$ single-blind study comparing topiramate with sustained-release bupropion in the depressive phase of bipolar disorder showed promising results for topiramate. ${ }^{45}$ This study, however, had significant methodological shortcomings. ${ }^{44}$ Furthermore, in a double-blind placebo-controlled study, topiramate was not found efficacious as an add-on treatment for schizo-affective disorder, bipolar type. ${ }^{46}$ Another, more recent, double-blind placebo-controlled trial, however, has reported topiramate to be as efficacious for the treatment of mania in adolescents with bipolar I disorder. ${ }^{47}$ Therefore, although no recommendation can be made regarding the use of topiramate in either adults or adolescents, one can expect further studies in this regard.

In a retrospective study, Carpenter found that only a small percentage of patients suffering from major depressive disorder improved when topiramate had been used as an add-on treatment. ${ }^{10}$ At present, however, the use of topiramate in the treatment of major depressive disorder is not supported scientifically, if not in fact dubious. There has been a case report of topiramate-induced depression. ${ }^{48}$

\section{Cautions}

As with all medication, topiramate has side-effects, and some are serious. For this reason, the decision to use it in conditions for which it has not been approved must not be taken lightly. Cereza et al. ${ }^{49}$ warned about serious adverse events when topiramate had been prescribed for conditions for which it was not approved. These side-effects include glaucoma and abnormal vision. Mula and Trimble ${ }^{50}$ remind clinicians that topiramate can also cause psychopathology as a side-effect. They found mood disorders (mostly a depressive disorder and 1 incidence of mania), aggressive behaviour, psychosis, anxiety, and personality changes as side-effects of topiramate. These authors observed that psychopathology was related to seizure control in a subgroup of patients. They mentioned that the role of forced normalisation, interlinked with interactions with other anti-epileptic drugs, could be relevant. They suggested slower titration for seizure control as a measure to prevent these side-effects. Furthermore, one must note that, in some of the abovementioned studies, subjects had to be withdrawn owing to side-effects, as well as noting their high drop-out rates.

\section{Conclusions}

Topiramate is an anti-epileptic medication that shows promise for psychiatric uses. One disappointing indicator from double-blind placebo-controlled trials is that topiramate appears inefficacious for mood disorders. At present, topiramate's use in psychiatry seems most promising for bulimia nervosa and BPD but, even in these disorders, much more research involving larger numbers of subjects over longer trial periods is necessary before clear evidence-based recommendations can be made. Although promising results in a double-blind placebo-controlled trial were found for alcohol and nicotine dependence, more and longer trials too are needed. Confounding factors make interpretation of studies involving topiramate and other psychiatric disorders difficult. Nevertheless, it seems worthwhile to investigate the use of topiramate in disorders of impulse control, PTSD, angry/aggressive behaviour, self-injury, and perhaps primary depressive disorders. It must be emphasised that no firm evidencebased recommendations can be made regarding any of these conditions.

Topiramate is clearly associated with weight loss. This side-effect could possibly be of use in selected cases, but there are no clinical guidelines as yet for its use in treating obesity or weight gain secondary to psychotropic medication. Some studies indicate that topiramate is well tolerated while others indicate that it is poorly tolerated, with significant and even serious side-effects. Topiramate may worsen anorexia nervosa, cause psychopathology in adults and cause behavioural problems in children with autistic spectrum disorders.

\section{References}

1. Ketter TA. Topiramate. In: Sadock BJ, Sadock VA, eds. Kaplan \& Sadock's Comprehensive Textbook of Psychiatry, 8th ed. Philadelphia: Lippincott Williams \& Wilkins, 2005: 2753-2756.

2. Nickel C, Tritt K, Muehlbacher M, et al. Topiramate treatment in bulimia nervosa patients: a randomized, double-blind, placebo-controlled trial. Int J Eat Disord 2005; 38: 295-300.

3. Hedges DW, Reimherr FW, Hoopes SP, et al. Treatment of bulimia nervosa with topiramate in a randomized, double-blind, placebo-controlled trial, part 2: improvement in psychiatric measures. J Clin Psychiatry 2003; 64: 1449-1454. 
4. Hoopes SP, Reimherr FW, Hedges DW, et al. Treatment of bulimia nervosa with topiramate in a randomized, double-blind, placebo-controlled trial, part 1: improvement in binge and purge. J Clin Psychiatry 2003; 64: 1335-1341.

5. Barbee JG. Topiramate in the treatment of severe bulimia nervosa with comorbid mood disorders: a case series. Int J Eat Disord 2003; 33: 468-472.

6. Felstrom A, Blackshaw S. Topiramate for bulimia nervosa with bipolar II disorder. J Psychiatry 2002; 159(7): 1246-1247

7. Knable M. Topiramate for bulimia nervosa in epilepsy Am J Psychiatry 200 1; 158(2): 322-323

8. Appolinario JC, Fontenelle LF, Papelbaum M, et al. Topiramate use in obese patients with binge eating disorder: an open study. Can J Psychiatry 2002; 47: 271-273.

9. Kotwal R, Guerdiikova A, McElroy SL, Keck PE Jr. Lithium augmentation of topiramate for bipolar disorder with comorbid binge eating disorder and obesity. Hum Psychopharmacol 2006; 21: 425-431

10. Carpenter LL, Leon Z, Yasmin S, Price LH. Do obese depressed patients respond to topiramate? A retrospective chart review. J Affect Disord 2002; 69(1-3): 25 1-255.

11. Rosenow, F, Knake S, Hebebrand J. Topiramate and anorexia nervosa. Am J Psychiatry 2002; 159: 211 2-2113.

12. McElroy SL, Frye MA, Altshuler LL, et al. A 24-week, randomized, controlled trial of adjunctive sibutramine versus topiramate in the treatment of weight gain in overweigh or obese patients with bipolar disorders. Bipolar Disord 2007; 9(4): 426-434.

13. Roy Chengappa KN, Schwarzman LK, Hulihan JF, et al. Adjunctive topiramate therapy in patients receiving a mood stabilizer for bipolar I disorder: a randomized, placebo-controlled trial. J Clin Psychiatry 2006; 67(1 1): 1698-1706.

14. Tramontina S, Zeni CP, Pheula G, Rohde LA. Topiramate in adolescents with juvenile bipolar disorder presenting weight gain due to atypical antipsychotics or mood stabilizers: an open clinical trial. J Child Adolesc Psychopharmacol 2007; 17(1): 129-134

15. Canitano R. Clinical experience with topiramate to counteract neuroleptic induced weight gain in 10 individuals with autistic spectrum disorders. Brain Dev 2005; 27 : 228-232

16. Swift R M. Topiramate for alcohol dependence: initiating abstinence. Lancet 2003 361: 1666-1667

17. Johnson BA, Ait-Daoud N, Bowden CL, et al. Oral topiramate for treatment of alcohol dependence: a randomised controlled trial. Lancet 2003; 361: 1677-1685.

18. Rubio $G$, Ponce $G$, Jimenez-Arriero MA, et al. Effects of topiramate in the treatment of alcohol dependence. Pharmacopsychiatry 2004; 37(1): 37-40.

19. Raguraman J, Priyadharshini RK, Chandrasekaran R. Effects of topiramate in alcohol dependence. Aust NZ J Psychiatry 2005; 39(8): 736-737.

20. Huguelet $P$, Morand-Collomb S. Effect of topiramate augmentation on two patients suffering from schizophrenia or bipolar disorder with comorbid alcohol abuse. Pharmacol Res 2005: 52: 392-394.

21. Komanduri R. Two cases of alcohol craving curbed by topiramate. J Clin Psychiatry 2003; 64: 612

22. Johnson BA, Ait-Daoud N, Akhtar FZ, Javors MA. Use of oral topiramate to promote smoking abstinence among alcohol-dependent smokers: a randomized controlled trial. Arch Intern Med 2005; 165: 1600-1605

23. Khazaal Y, Cornuz J, Bilancioni R, Zullino DF. Topiramate for smoking cessation Psychiatry Clin Neurosci 2006; 60: 384-388

24. Kampman KM, Pettinati H, Lynch KG, et al. A pilot trial of topiramate for the treatment of cocaine dependence. Drug Alcohol Depend 2004; 75: 233-240.

25. Loew TH, Nickel MK, Muehlbacher $M$, et al. Topiramate treatment for women with borderline personality disorder: a double-blind, placebo-controlled study. J Clin Psychopharmacol 2006; 26: 61-66

26. Nickel MK, Nickel C, Mitterlehner FO, et al. Topiramate treatment of aggression in female borderline personality disorder patients: a double-blind, placebo-controlled study. J Clin Psychiatry 2004; 65: 1515-1519.

27. Nickel MK, Nickel C, Kaplan P, et al. Treatment of aggression with topiramate in male borderline patients: a double-blind, placebo-controlled study. Biol Psychiatry 2005; 57: 495-499

28. Do Prado-Lima PA, Kristensen CH, BacaltchuckJ. Can childhood trauma predict response to topiramate in borderline personality disorder? J Clin Pharm Ther 2006 31: 193-196.

29. Cassano P, Lattanzi L, Pini S, et al. Topiramate for self-mutilation in a patient with borderline personality disorder. Bipolar Disord 2001:3:161.
30. Gobbi G, Gaudreau PO. Leblanc N. Efficacy of topiramate, valproate, and thei combination on aggression/agitation behavior in patients with psychosis. J Clin Psychopharmacol 2006; 26: 467-473

31. Nickel C, Lahmann C, Tritt $K$, et al. Topiramate in treatment of depressive and anger symptoms in female depressive patients: a randomized, double-blind, placebocontrolled study. J Affect Disord 2005; 87: 243-252.

32. Fhager $B$, Meiri IM, Sjogren M, Edman A. Treatment of aggressive behavior in dementia with the anticonvulsant topiramate: a retrospective pilot study. Intern Psychogeriatr 2003; 15(3): 307-309

33. Kossoff EH, Pyzik PL. Improvement in alertness and behavior in children treated with combination topiramate and vagus nerve stimulation. Epilepsy Behav 2004; 5: 256 259.

34. Janowsky DS, Kraus JE, Barnhill J, et al. Effects of topiramate on aggressive, selfinjurious, and disruptive/destructive behaviors in the intellectually disabled: an openlabel retrospective study. J Clin Psychopharmacol 2003; 23(5): 500-504

35. Lochner C. Seedat S, Niehaus DJ. Stein DJ. Topiramate in the treatment of trichotillomania: an open-label pilot study. Clin Psychopharmacol 2006; 21: 255259

36. Dannon PN, Lowengrub K, Gonopolski Y, et al. Topiramate versus fluvoxamine in the treatment of pathological gambling: a randomized, blind-rater comparison study. Clin Neuropharmacol 2005; 28: 6-10:

37. Dannon, Pinhas N. Topiramate for the treatment of kleptomania: a case series and review of the literature. Clin Neuropharmacol 2003; 26: 1-4.

38. Grant JE. SPECT imaging and treatment of pyromania. J Clin Psychiatry 2006; 67:6

39. Berlant J, Van Kammen DP. Open-label topiramate as primary or adjunctive therapy in chronic civilian posttraumatic stress disorder: a preliminary report. / Clin Psychiatry 2002; 63(1): 15-20.

40. Berlant JL. Prospective open-label study of add-on and monotherapy topiramate in civilians with chronic nonhallucinatory posttraumatic stress disorder. BMC Psychiatry 2004; 4: 24

41. Suppes T. Review of the use of topiramate for treatment of bipolar disorders. J Clin Psychopharmacol 2002; 22: 599-609.

42. Powers PS, Sachs GS, Kushner SF, et al. Topiramate in adults with acute bipolar I mania: pooled results. Presented at the 157th Annual Meeting of the American Psychiatric Association, New York. 2004. Quoted in: Delbello MP, Findling RL, Kushner $\mathrm{S}$, et al. A pilot controlled trial of topiramate for mania in children and adolescents with bipolar disorder. J Am Acad Child Adolesc Psychiatry 2005; 44(6): 539-547

43. Delbello MP, Findling RL, Kushner S, et al. A pilot controlled trial of topiramate for mania in children and adolescents with bipolar disorder. J Am Acad Child Adolesc Psychiatry 2005; 44(6): 539-547

44. Vasudev K, Macritchie K, Geddes J, et al. Topiramate for Acute Affective Episodes in Bipolar Disorder. Cochrane Database of Systematic Reviews 2006; (1):CD003384.

45. Mclntyre RS, Mancini DA, McCann S, et al. Topiramate versus bupropion SR when added to mood stabilizer therapy for the depressive phase of bipolar disorder: a preliminary single-blind study. Bipolar Disord 2002; 4(3): 207-213

46. Roy Chengappa K, Kupfer DJ. Parepally H et al. A placebo-controlled, randomassignment, parallel-group pilot study of adjunctive topiramate for patients with schizoaffective disorder, bipolar type. Bipolar Disord 2007; 9(6): 609-617

47. DelBello MP, Kushner S, Wang D, et al. Topiramate treatment of acute mania in adolescents with bipolar I disorder. 42nd Annual Meeting of the American College of Neuropsychopharmacology, San Juan, Puerto Rico, 7 - 11 December 2003. Quoted in: Ketter TA. Topiramate. In: Sadock BJ, Sadock VA, eds. Kaplan \& Sadock's Comprehensive Textbook of Psychiatry, 8th ed. Philadelphia: Lippincott Williams \& Wilkins, 2005: 2753-2756

48. Klufas A, Thompson D. Topiramate-induced depression. Am J Psychiatry 2001 158(10): 1736

49. Cereza G, Pedrós C, Garcia N Laporte J-R. Topiramate in non-approved indication and acute myopia or angle closure glaucoma. Br J Clin Pharmacol 2005; 60: 576579

50. Mula M, Trimble MR. The importance of being seizure free: topiramate and psychopathology in epilepsy. Epilepsy Behav 2003; 4: 430-434 